\title{
生物磁感应: 在质疑和希望中前行的研究领域
}

章鹏 ${ }^{1,2}$, 谢灿 ${ }^{1,2,3^{*}}$

1. 中国科学院合肥物质科学研究院, 强磁场科学中心, 合肥 230031 ;

2. 中国科学技术大学, 合肥 230026 ;

3. 国际磁生物学前沿研究中心(iMFRC), 合肥 230031

* 联系人, E-mail: canxie@hmfl.ac.cn

指南针，作为中国的四大发明之一，是航海家们的“眼 睛”, 是人类航海活动和探索新大陆过程中必不可缺的工具 之一. 在茫茫大海上, 人们借助指南针来确定方向. 然而, 自 然界中有很多生物并不需要借助任何外物便可完成令人惊 叹的长距离迁徙活动, 如北极燕鸥每年往返于地球南北极、 可可西里藏羚羊上千公里大迁徙、黑脉金斑蝶四代接力往 返北美大陆等 ${ }^{[1]}$. 那么, 动物迁徙过程中的导航和定位是如何 实现的？仿佛这些生物都自带尚不被我们所知的“生物指南 针”. 虽然“生物能够感知地磁场”这一观点在最初遭到了质 疑和嘲笑, 但是, 随着迁徙鸟类能感知地磁场的证据陆续被 发现, 生物磁感应相关研究慢慢丰富起来. 在许多生物中, 人 们已经发现了其感知地磁场的确丵证据, 并提出了感磁机制 的不同模型或假说. 每种模型都有相应的物质基础和实验数 据支持, 但也存在一定的局限性. 截至目前, 没有任何一种模 型能够很好地解释动物迁徙和生物导航中的所有问题. 当然, 由于生物多样性的存在, 在漫长的进化历程中, 不同的物种 也可能演化出不同的感磁机制和生物导航策略. 尽管生物感 知磁场的机制尚未完全阐明，但人们已经明确: 有些生物能 以某种方式实现对地球磁场的检测, 这种能力称之为磁感应 (magnetoreception), 或称为磁感觉 (magnetic sense). 为了将这 种特殊的感觉系统区别于我们常说的五感(视觉、听觉、嗅 觉、味觉和触觉), 磁感应也常常被戏称为“第六感”.

需要注意的是, 在“磁感应”这一定义中, 我们更多的是 强调生物对磁场信号的接收(reception), 和利用的能力. 磁感 应有时候也被称为磁感知(magneto-perception) 以强调动物神 经系统对地磁场的感知(perception)和解读机制. 考虑到从单 细胞的趋磁细菌到多细胞的动植物都存在对地磁场的检 测、响应和利用的现象, 在这些物种中如趋磁细菌和植物, 并不涉及神经系统的参与, 因此, 本文将英文学术名词 $\mathrm{mag}$ netoreception统一翻译为“磁感应”.

\section{1 生物磁感应的研究历史}

我们有眼睛, 可以看见可见光波段内的各种颜色; 我们 有耳朵, 可以听见20 20000 Hz频率范围内的声音; 但是我们

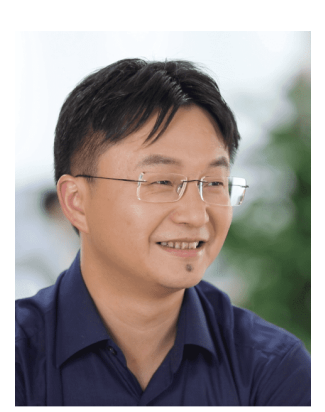

谢灿中国科学院强磁场科学中心 研究员, 中国工程物理研究院北京计 算科学中心兼职教授. 主要研究方向 为磁感应和生物导航原理、自然界 中的结构色以及生物磁控技术.

身处偌大的地磁场中，却并不能感知到它的存在．随着指南 针的发明和现代磁科学与地球科学相关研究的陆续开展, 我 们逐步对地磁场有了一些初步的理解. 根据 “发电机理论”,[2,3], 在地球地核内核和地幔之间, 是一层液态的地核外核, 由于 内核与地幔层之间运动步调不是一致的, 这些流体的对流运 动就产生了地磁场. 地球磁场可以近似地看作磁偶极子场, 地磁场的南极在地理北极附近, 而地磁北极在地理南极附近. 地磁场强度虽然只有约 0.5 高斯(生活中的一块小永磁铁便可 达到上千高斯), 但其覆盖范围可从地球内部向外延伸至太 空, 并与太阳风作用形成巨大的磁层, 像是在地球的外围形 成了一个保护层, 使地球和地球上的生物可以免受太阳风和 各种高能宇宙射线的影响, 得以正常生存 ${ }^{[4,5]}$. 虽然我们人类 “身在场中不知场”, 但许多动物却能感应地磁场, 并利用地磁 场的信息进行定位、导航和长距离迁徙.

生物需要对外界的感知, 这种感知包括我们常说的五感 (视觉、听觉、嗅觉、味觉和触觉), 也包括在五感以外的难 以计数的感知系统, 如人类的前庭感觉(vestibular sense)、动 物的温度感觉(thermoreception, 又称thermosensation)、鲨鱼 和一些鱼类的电场感觉(electroreception), 以及迁徙动物的磁 感应(magnetoreception, 又称磁感觉magnetic sense)等. 而在这 些感觉系统中, 磁感应与迁徙动物的长距离导航密不可分, 也是迄今为止我们在动物学和行为学上了解较多, 但在分子 机理上了解最少的一种感觉系统. 
生物磁感应的领域从一开始就在质疑和希望中前行. 生 物感磁的最初研究证据来自俄罗斯动物学家Middendorf ${ }^{[6]}$, 他记录并绘制了多种候鸟的迁徙路线，据此发现不同的候鸟 在迁徙中似乎都遵循朝北飞行的趋势，并在19世纪50年代发 表了相关研究成果, 认为候鸟能够利用地球的磁场进行定 位 $^{[7]}$. 但该观点在当时受到了不少质疑，很长一段时间内没 有新的证据提出而逐渐沉寂. 直到20世纪美国物理学家Yeagley和Whitmore ${ }^{[8]}$ 做了一个实验，他们分别将等质量的小块磁 铁和铜片绑在鸽子的翅膀上并将这些鸽子放飞, 最后绑有铜 片的 10 只鸽子中有 8 只成功归巢，而绑有小磁铁的 10 只鸽子 中只有 1 只回到了巢中. 这个实验很好地反映了磁铁确实可 以干扰鸽子的定位导航.

动物能否感知地球磁场, 经历了长时间的争议和辩论、 在1966年才迎来了第一个关键的转折点. 经过两年的行为学 实验, 德国科学家Wiltschko和Merkel ${ }^{[9]}$ 在实验中发现, 知更鸟 可以通过感知人工磁场进行定位，推论鸟类迁徙和导航中依 靠了地磁场信息，文章于1966年发表在Verh Dtsch Zool Ges 上. 其后, Wiltschko夫妇(Wolfgang Wiltschko和Roswitha Wiltschko $)^{[10]}$ 于 1972 年在Science 上发文: 知更鸟感知磁场的 原理不同于经典的指南针，因为知更鸟只能感知地磁场中某 处磁感应强度矢量与水平面的夹角，而无法区分南北极，文 中将这种磁感受器称为磁倾角罗盘. 1976年, Wiltschko夫妇 和美国康奈尔大学的合作者 ${ }^{[11]}{ }^{-}$关合在Science上再次发文，报 道了一种在北美常见的迁徙鸟类静蓝彩鸥(Indigo buntings, Passerina cyanea)对地球磁北极和人工磁场磁北极的感知能 力. 至此, 历经了 10 年的努力, 迁徙动物能感知地磁场的概念 终于被学术界广泛接受.

20 世纪70 80年代是生物磁感应研究的黄金时代. 关于 磁感应机制的各种假说层出不穷, 盛行一时, 几种主流假说 的代表人物都在那个年代开始崭露头角. 磁铁矿颗粒假说直 接脱胎于磁小体的发现. 1975年, Blakemore ${ }^{[12]}$ 分离得到了一 种名为螺旋折叠体的厌氧菌，在显微镜下观察时发现，该菌 总是移向载玻片的一端，且这不是趋光性，因为在黑暗的情 况下也是如此. 随后发现, 如果在载玻片附近放一块小磁铁, 细菌就会向磁铁方向移动. 对该细菌进行超微结构观察时, Blakemore找到了细菌的趋磁原因：其体内含有15 20个含铁 的微小磁性颗粒，这些颗粒组装时排成一条直线，形成了一 个较长的“条形磁铁”一磁小体, 因此推测该结构可以感知 地磁场的方向, 从而指引它游向水中更深处 (厌氧环境). 进一 步的研究证实, 磁小体是由 $\mathrm{Fe}_{3} \mathrm{O}_{4}$ 和 $\mathrm{Fe}_{3} \mathrm{~S}_{4}$ 构成的被膜结构, 是 单磁畴晶体, 可以感应地磁场. 该研究促使人们试图在其他 感磁生物中寻找类似磁小体的结构, 也成为了支持磁铁矿假 说的有力证据. 有趣的是, 最近的一篇综述提到, 某些单细胞 真核生物可以通过捕食趋磁细菌或是与之共生而获得“磁感 应”能力 ${ }^{[13]}$. 与此同时, 其他一些科学家相继在各种生物中分 别发现磁铁矿的存在, 从而催生了这一假说的提出, 其中有
一些较为重要的发现, 如Gould等人 ${ }^{[14,15]}$ 在蜜蜂腹部发现磁 铁矿, Lowenstam ${ }^{[16]}$ 在海洋软体动物中也发现了磁铁矿的存 在等. 自由基对假说则由物理学家推动. 1976年, 在德国物理 学家和量子化学家Schulten等人 ${ }^{[17]}$ 通过理论推算和数据分析 发表的一篇关于量子纠缠态解释高速三重态反应的文章中, 实验数据清楚地表明, 微弱的磁场对化学反应能够产生影响. 两年后，结合Wiltschko等人 ${ }^{[10,11]}$ 关于知更鸟利用地磁场迁徙 导航的相关研究, Schulten和Wolynes ${ }^{[18]}$ 进一步发文指出, 鸟 类的磁感应机制涉及自由基对的纠缠态. 这引发了后续的相 关研究, 进一步催生了基于隐花色素蛋白(cryptochrome, Cry) 的磁感应化学自由基对模型.

20 世纪80年代后，由于科学技术的发展进步，生物磁感 应的研究成果也进一步丰富起来, 许多生物的磁感应能力陆 续得到证实. 1980年, Quinn ${ }^{[19]}$ 通过实验证实了一种存在迁徙 行为的红鲑鱼 (Oncorhynchus nerka) 具有磁感应能力. 他发现, 这种鱼在迁徙过程中存在明显的方向偏好，并推测地磁场是 其洄游时获取方向信息的重要来源. 1986年, Phillips ${ }^{[20]}$ 在 Science上报道了一种迁徙蝾螈(Notophthalms viridesens)的两 种感磁机制: 一种是类似于鸟类极性罗盘的轴向指南针; 另 一种则是其特有的可响应地磁极性的磁感应通路. 1994年, $\mathrm{Hsu}$ 和 $\mathrm{Li}^{[21]}$ 在蜜蜂的滋养层细胞中发现富含超顺磁性磁铁矿, 且这些细胞受到神经系统的刺激, 因而推测蜜蜂的滋养层细 胞可能具有磁感应功能. 1995 2003年, Ernst和Lohmann ${ }^{[22]}$ 在 一项关于一种迁徙龙虾(Panulirus argus)的研究中首次表明, 该龙虾是当时已报道的唯一可以同时感知磁场倾角和方向 等信息的无脊索动物, 其体内的磁铁矿颗粒可能是其感磁的 关键. 除此之外, 海龟 ${ }^{[23]}$ 、蝙蝠 ${ }^{[24]}$ 、磁白蚁 ${ }^{[25]}$ 、鼠鼠 ${ }^{[26]}$ 和 狗 ${ }^{[27}$ 等生物也被报道具有磁感应能力. 截至2006年，在各个 动物门类中, 已报道的具有磁感应能力的物种达到了 48 种, 其中鸟类和昆虫占了大半 $(\text { 表 } 1)^{[28]}$.

\section{2 生物磁感应假说}

自20世纪50年代至今, 综合来看, 备受关注的磁感应假 说主要有电磁诱导模型、磁铁矿颗粒模型、依赖隐花色素 的化学自由基对模型、生物指南针模型. 这些假说均有一定 的实验证据支持，同时也存在一定的局限或不足，近年来也 不断有新的模型被提出.

\section{1 电磁诱导模型}

物理学上的电磁感应(electromagnetic induction), 是指放 在变化磁通量中的导体, 会产生电动势. 此电动势称为感应 电动势或感生电动势, 若将此导体闭合成一回路，则该电动 势会驱使电子流动, 形成感应电流(感生电流 ${ }^{[30,31]}$. 1678年, 意大利解剖学家Stefano Lorenzini发现, 鲨鱼和鳐鱼头部前端 嘴巴附近散布许多胡渣似的体孔，对其解剖后发现，每个体 孔对应着一条透明导管的端口，向内一直延伸至鲨鱼头部深 
表 1 截至2006年已报道的具有磁感应能力的物种汇总 ${ }^{[28]}$

Table 1 Animals demonstrated to use a magnetic compass by $2006^{[28]}$

\begin{tabular}{|c|c|c|c|c|}
\hline 生物类别 & 分类等级: 目 & 分类等级: 科 & 分类等级: 种 & 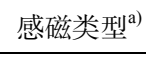 \\
\hline \multicolumn{5}{|l|}{ 软体动物门 } \\
\hline 腹足纲 & 1目 & 1科 & 1种 & 未知 \\
\hline \multicolumn{5}{|l|}{ 节肢动物门 } \\
\hline 甲壳纲 & 3目 & 3科 & 5 种 & 极性罗盘 \\
\hline 昆虫纲 & 6目 & 7科 & 9种 & 极性罗盘 \\
\hline \multicolumn{5}{|l|}{ 脊索动物门 } \\
\hline 软骨鱼纲 & 1目 & 1科 & 1 种 & 未知 \\
\hline 硬骨鱼纲 & 2目 & 2科 & 4种 & 极性罗盘 \\
\hline 两栖纲 & 1目 & 2科 & 2种 & 磁倾角罗盘 \\
\hline 爬行纲 & 1目 & 2科 & 2种 & 磁倾角罗盘 \\
\hline 鸟纲 & 4目 & 12科 & 21 种 & 磁倾角罗盘 \\
\hline 哺乳纲 & 2目 & 2科 & 3 种 & 极性罗盘 \\
\hline
\end{tabular}

a) “极性罗盘”指能感知磁场的极性(南北极), “磁倾角罗盘”指能感知磁场的倾角

处的几大块透明胶状物中，导管内充满了晶状胶体物质. 起 初人们推测, 该结构的功能是分泌黏液至鲨鱼体表, 虽然Lorenzini终其一生没能找到答案，但他坚信该结构一定有某种 不为人知的功能. 后来该结构被称作劳伦氏壸腹(ampullae of Lorenzini). 近3个世纪后, Kalmijn ${ }^{[32]}$ 于1971年指出, 管中的胶 状物质具有高导电性，整个导管可以起到导体的作用，在地 磁场下对微小电压的改变非常敏感. 因此, 靠着这个技能, 纁 鱼可以在无光的深海和浑浊的水域中进行捕食. 其周围若有 生物游动, 便会产生水流扰动, 进而引起微小的电压变化. 借 助劳伦氏壸腹对这种细微变化的检测，鲨鱼便能依靠这“第 六感”在黑暗中轻松狩猎(图1).

然而，该模型提出后也存在一些问题，如尽管板鳃类动 物的电受体对变化的电压很敏感, 但是却不能感应直流电压, 而且在地磁场下涌动的洋流自身也会产生电场. 1995年, Pau$1 i n^{[33]}$ 指出, 鲨鱼或鳐鱼是通过游动时头部前后摆动产生震荡 电场, 同时头部的运动可能还起到了“过滤”的作用, 去除了洋 流本身产生电场的无关刺激. 不过, 总体看来, 电磁诱导磁感 应模型似乎不具有普适性，因为只在鲨鱼和鳐鱼等板鳃类动 物中发现了对电场如此极端敏感的电感受器. 因此，电磁诱 导模型似乎只能用于解释板鳃类动物的磁感应. 另外，电磁 诱导假说还需要满足至少两个条件：首先，动物的体型足够 大才有可能达到电磁感应的效果; 其次, 还需要海水的高电 导率. 换言之，这一假说即使成立，但由于其适用范围非常 乍, 从而被慢慢淘汰.

不过, 2019年, Keays课题组 ${ }^{[34]}$ 将研究对象转向鸽子, 提 出了鸽内耳电磁感应的一种可能的磁感应机制. 他们在旋转

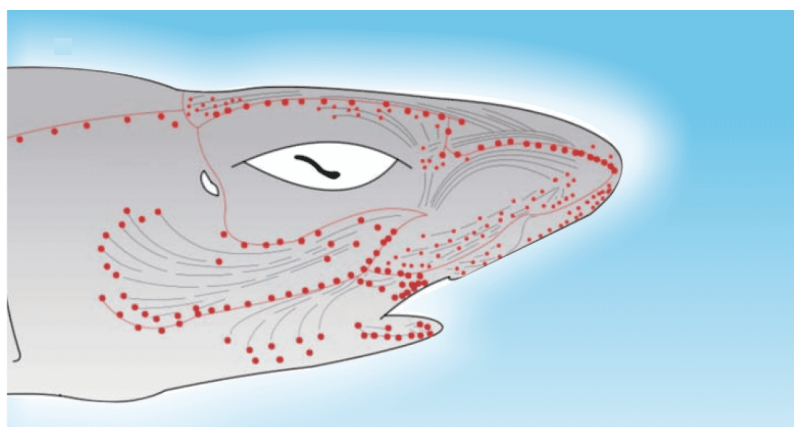

图 1 鲨鱼头部侧视图, 展示由劳伦氏壶腹构成的电受体结构 ${ }^{[29]}$. 其 中, 红点表示鲨鱼头部表皮上的体孔，即劳伦氏壶腹; 灰线表示充满 胶状物质的导管, 其具有高导电性; 红线表示鲨鱼的侧线, 即鱼类特 有的感觉器官

Figure 1 Side view of a shark's head, showing the electroreceptor structure composed of the ampullae of Lorenzini ${ }^{[29]}$. The red dots represent the body holes on the shark's head, which are the ampullae of Lorenzini electroreceptors; the gray lines represent the jelly-filled canals, which have high conductivity; the red lines represent lateral lines of the shark, which is the unique sensory organ of fish

磁场下对固定头部的鸽子进行磁刺激，跟踪检测到了鸽子前 庭核神经元活动. 由于发现磁刺激导致的神经元活动不需要 光的参与, 且排除了磁铁矿颗粒的存在, 因此, 他们推测, 鸽 子内耳半规管内的电磁感应介导了磁感应过程. 随后，他们 发现了鸽子内耳中存在电压钲离子通道的剪接异构体，且该 剪接异构体已被证明在鳐鱼和鲨鱼中介导电接收, 从而推测, 鸽子是在半规管内通过电磁感应来检测磁场的. 这一最新研 究似乎为搁置已久的电磁诱导理论提出了新的可能. 


\section{2 磁铁矿颗粒模型}

趋磁细菌中磁小体的发现, 以及趋磁细菌对地球磁场的 快速响应，启发研究人员开始寻找其他生物体内的“磁小体”, 也即磁铁矿颗粒的存在. 尽管许多趋磁细菌装配磁小体的同 源基因在高等生物中并未发现, 研究人员还是在蜜蜂、鸟 类、鱼类和蚂蚁等动物中发现了磁铁矿富集区 ${ }^{[35]}$. 基于对趋 磁细菌的认识, 磁铁矿颗粒模型假说认为, 在感磁生物的特 定部位可能存在类似于趋磁细菌中磁小体一样的细小磁铁 矿颗粒，在地磁场的作用下，这些颗粒磁化并呈线性排列装 配成单磁畴晶体. 因其具有顺磁性，在地磁场下始终沿磁感 线排列, 由此感磁生物可以获取实时的地磁信息并作出响应.

1978年，Gould等人 ${ }^{[14]}$ 首先在已死的蜜蜂成虫上通过强 磁场作用检测到剩磁，随后通过非磁性工具解剖进一步将磁 性物质定位在了蜜蜂的腹部前端，从而提出蜜蜂的腹部可能 存在磁铁矿颗粒. 几年后, Kuterbach等人 ${ }^{[36]}$ 进一步指出, 蜜蜂 的含铁细胞是腹部节段处的卵母细胞. 之后关于蜜蜂的磁感 应研究一直颇具争议 ${ }^{[21,39 ~ 41]}$. 2018年，Shaw等人 ${ }^{[42]}$ 将多模态 成像与分析的方法应用于蜜蜂，确认了蜜蜂腹部中富含铁的 事实, 与前人的研究结论一致.

1979年, 美国鸟类学家Walcott等人 ${ }^{[43]}$ 在鸽子鸟潒也即头 部硬脑膜和头骨之间的区域发现了磁铁矿，且该部位还存在 神经细胞. 这让人不由得联想磁铁矿接受地磁信息后通过神 经传导人大脑，刚好构成一条完整的通路. 随后又有更多研 究人员在不同鸟类中发现了磁铁矿颗粒 ${ }^{[38,44]}$. 而且 2004 年 Mora等人 ${ }^{[45]}$ 的行为学实验中发现, 无论是在鸽子的鲒部绑上 小块磁铁或是切断其眼部三叉神经, 都可使鸽子感磁能力丧 失或受损. 磁铁矿颗粒的发现和与之相符的行为学实验表明, 鸟类喙部的磁铁矿颗粒在磁感应过程中发挥着重要作用.

1997年，Walker等人 ${ }^{[46]}$ 以虹䲡鱼为研究对象，通过研究 其在磁场下的行为和电生理反应, 声称在虹鳟鱼鼻腔内找到 了磁感应细胞, 并指出嗅觉障碍可能会导致磁感应障碍. 因
此, 虹鳟鱼似乎成了能“嗅”到磁感应的生物. 2012年, Eder等 人 $^{[37]}$ 分离了虹䲡鱼的嗅觉上皮组织细胞, 发现其中 100 个左 右的游离细胞中存在 1 4个会随着磁场旋转而旋转的细胞, 且每个这样的细胞中都含有 1 个包涵体，随后通过共聚焦反 射成像技术发现, 其中有能响应磁场刺激的单畴磁铁矿晶体, 而包涵体的X射线能量色散谱图也显示显著的铁峰，这一研 究成为磁铁矿颗粒模型适用于虹鳟鱼的有力证据. 诸如此类 的实验结果加上磁铁矿与磁场固有的相互作用关系使人们 更加相信, 磁铁矿颗粒参与了生物感磁过程(图2).

然而，也是在2012年，David Keays实验室的Treiber等 人 $^{[47]}$ 在Nature发文称，通过核磁共振扫描仪得到的数据表明， 鸽子上潒部富含铁的细胞团只是巨噬细胞，参与免疫过程， 而与磁感应无关. 3 年后, David Keays实验室 ${ }^{[48]}$ 再次发文指 出，通过利用“磁镜”耦合单细胞相关的光电显微镜(correlative light and electron microscopy, CLEM)技术鉴定鸽子和鳟 鱼中所谓的含磁铁矿的细胞发现，这些细胞尽管显示具有较 大的磁矩，但观察到的所有电子致密结构都是细胞外的，而 非生物体产生, 从而认为这些细胞的磁矩是由于实验污染导 致的.

尽管在脊索动物中尤其是鸟㗒中磁铁矿颗粒和磁感应 的关联受到挑战, 但通过鸟类行为学和神经生物学实验发现 的三叉神经可能参与磁感应的证据目前尚未动摇, 并被磁感 应研究领域沿用至今. 同时, 相比于脊索动物中磁铁矿颗粒 鉴定过程中的争议, 磁铁矿颗粒在节肢动物(尤其是昆虫)中 的存在仍能找到较为一致的证据. 其中最为经典的是蜜蜂腹 部磁铁矿的证明. 2016年有学者先通过实验证明, 蜜蜂在全 黑暗的环境中仍有正常的磁场响应和方向感，认为Cry可能 不是感磁的关键因素, 再通过训练蜜蜂建立经典的条件反射, 使之将磁场刺激与蔗糖奖励联系起来. 而当切断蜜蜂腹部和 胸部之间的腹神经索后，蜜蜂则不再对磁场刺激作出反应， 从而推断，是蜜蜂腹部的磁铁矿作为感磁受体并将磁信号通
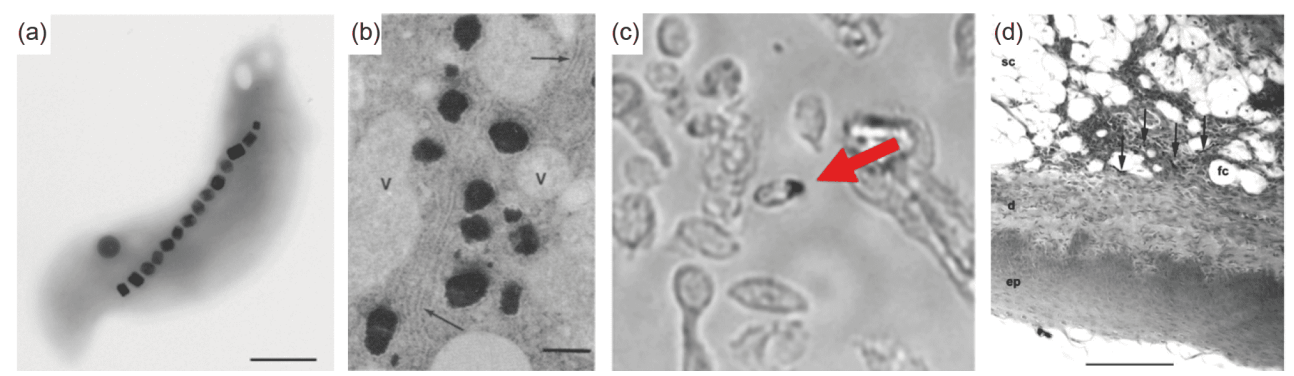

图 2 (网络版彩色)几种生物体内的铁颗粒 ${ }^{[13,36-38]}$. (a) 透射电子显微镜下趋磁细菌及其胞内的磁小体. (b) 高倍透射电子显微镜下蜜蜂细胞中 含铁颗粒(深色颗粒)的区域. (c) 虹䲡鱼嗅上皮细胞中的铁颗粒(箭头所指细胞内深色区域). (d) 鸽子上喙内层组织中的铁颗粒(箭头所指, 普鲁士 蓝染色)

Figure 2 (Color online) Iron particles in several organisms ${ }^{[13,36-38]}$. (a) Transmission electron microscope images of magnetotactic bacteria showing intracellular chain-assembled magnetosomes. (b) High-magnification transmission electron microscope image of honeybee cells showing iron containing particles (dark granules) inside the cell. (c) Iron particles in the cell from dissociated trout olfactory epithelium (the dark area in the cell indicated by the arrow). (d) Iron particles in the inner skin of the upper beak of homing pigeons (arrows, Prussian Blue [PB] counterstaining) 
过腹神经索传递给大脑 ${ }^{[49]}$. 还有学者通过超导量子干涉仪直 接对冻干并制成颗粒状的蜜蜂不同体段进行分析发现, 在蜜 蜂腹部存在明显的磁滞回线, 但在胸部或头部没有, 从而推 断, 在蜜蜂腹部存在铁磁物质 ${ }^{[50]} .2019$ 年, $\mathrm{Hsu}$ 等人 ${ }^{[51]}$ 更是通 过RNA干扰技术找到了与蜜蜂腹部铁颗粒形成和沉积形态 相关的基因(ferritin2 和ferritin1), 为进一步探索蜜蜂的磁感应 机制提供了新思路. 另外, 近年来关于其他节肢动物中存在 铁颗粒沉积的证据也时有报道, 如切叶蚁的头部和触角 ${ }^{[2]}$ 、 褐飞風的腹部 ${ }^{[53]}$ 、蚂蚁的触角 ${ }^{[54]}$ 、活体龙虾 ${ }^{[22]}$ 、活体美洲 大蠊 ${ }^{[55]}$ 等, 表明这一假说仍然存在着生命力, 也暗示着可能 在不同的物种中存在着不同的磁感应机制.

\section{3 依赖隐花色素的化学自由基对模型}

在磁铁矿假说提出的同一历史时期，另一种假说也慢慢 成型. 自1978年德国化学家Schulten和Wolynes ${ }^{[18]}$ 提出磁感应 的化学自由基对假说的初步模型, 指出鸟类的磁感应机制涉 及了自由基对的纠缠态后，他们开始寻找生物体内能够产生 自由基的生化分子. 同时期, 有学者对信鸽也进行了一个实

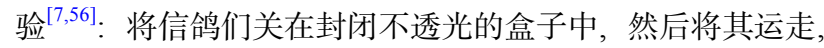
打开盒子将这些信鸽放飞时发现, 它们出现了归巢困难, 由 此得出信鸽在记录位置信息时需要光参与的结论. 然而, 这 个寻找的过程是漫长的. 整整20年后，1998年Stanewsky等 人 $^{[57]}$ 才在果蝇的眼睛中发现了隐花色，这是一种能被光激发 产生自由基的蛋白分子. 隐花色素的特征非常符合Schulten 的预期, 因此Schulten研究团队 ${ }^{[58]}$ 于 2000 年发表了他们的研 究成果, 指出隐花色素很可能就是鸟类磁导航过程中的关键 分子, 并大胆推测了感磁过程: 首先是隐花色素中的光敏色 素分子FAD(flavin adenine dinucleotide)吸收一个蓝光光子的 能量, 并由此引起分子中电子的跃迁, 留下一个空轨道; 其次 一个来自邻近保守色氨酸中且处于量子纠缠态的电子来到 该空轨道，此时这对被分离的电子由于量子纠缠同时具有自 旋单态和三重态; 最后, 两种状态的微妙平衡可由地磁场的 方向决定，并通过某种方式将此信息传递给大脑，使生物体 可以对地磁信息作出响应(图3).

当然，在2000年时依赖隐花色素的化学自由基对模型还 只是停留在Ritz等人 ${ }^{[58]}$ 的理论推导层面，更多的实验证据在 之后才慢慢积累起来. 2004年, Wiltschko夫妇等人 ${ }^{[59,60]}$ 联手 寻找量子指南针和经典指南针之间的区别，他们发现，从磁 场的振荡频率来看, 经典指南针会受低频振荡磁场的影响, 而量子指南针则能迅速响应高频磁场. 鉴于如此明显的差异, 他们对知更鸟进行了不同频率震荡磁场的干扰，结论证实， 高频振荡磁场能干扰知更鸟的导航能力, 这足以说明是量子 指南针在起作用. 2007年, Mouritsen课题组 ${ }^{[61]}$ 在园莺视网膜 中分离到了隐花色素分子, 并证实在蓝光下该分子能够产生 自由基对, 且其存在的时间足以响应地磁场. 2008年, Reppert 课题组 ${ }^{[62]}$ 通过实验发现，敲除了 $C r y$ 基因的果蝇会失去磁感

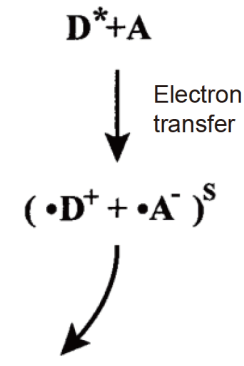

Singlet products

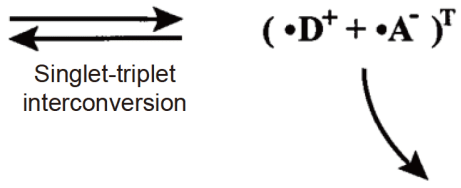

Triplet products
图 3 依赖磁场的化学自由基对反应模式 ${ }^{[58]}$. D表示电子供体(donor), A表示电子受体(acceptor). 自由基对由一个电子从供体转移到 受体而形成, 其状态受外部磁场影响在单重态和三重态之间转换 Figure 3 The magnetic field-dependent reaction of the chemical radical pair ${ }^{[58]}$. D represents an electron donor and $\mathrm{A}$ represents an electron acceptor. The radical pair is generated by an electron transfer from a donor molecule D to an acceptor molecule A, while an external magnetic field affects interconversion between singlet and triplet states of the radical pair

应能力, 进一步证实了这一蛋白分子在磁感应过程中的重要 性. 近年来, Hore课题组 ${ }^{[63,64]}$ 从物理学、化学和生物学等多方 面系统且完整地总结了自由基对假说的基本原理和支撑证 据. 他们指出, 至少对鸟类而言, 磁脉冲实验和麻醉鸟嘴并未 破坏其磁导航系统，因此鸟类的磁接收系统并不是基于铁氧 化物的机制; 相反地, 射频磁场实验和神经生物学实验的结 果都指向隐花色素是潜在的磁受体. 不过, 目前仍然缺乏隐 花色素是磁受体的确丵证据. 另外, 基于隐花色素蛋白的相 关特点, 2016 年该课题组 ${ }^{[6]}$ 成功合成了一个人造黄素蛋白磁 受体模型，其表现出了优异的磁敏特性，这为今后体外蛋白 的磁感应研究提供了新思路. 2019年, Takahashi课题组 ${ }^{[66]}$ 解 析了鸽子的Cry4的晶体结构, 并发现在鸽子的Cry4结构中具 有异常高的光还原量子产率. 这可以为动物在弱光下的夜间 迁徙找到解释，该研究为自由基对模型提供了有力的实验 证据.

在这一假说中, 隐花色素是包括鸟类在内的许多感磁生 物导航过程中必不可少的关键分子, 对地磁场的检测基于量 子化学的原理. 在Schulten和Hore为代表的一系列量子物理 学家和量子化学家的推动下, 在原理的阐述上取得了长足的 进展, 并得到了Mouritsen等一系列动物行为学家的支持, 在 磁感应领域的影响力逐渐扩大. 然而, Cry蛋白中电子自旋状 态的改变如何被生物的细胞信号系统识别则成了另一个谜 团. 此外, 自由基对的量子纠缠状态似乎只能感受磁倾角的 方向信息, 要想获取全部的地磁信息包括磁场强度和磁极的 检测, 依赖隐花色素的磁感应系统似乎还缺少其他组件 ${ }^{[77,68]}$.

\section{4 生物指南针模型}

2015年, 我们课题组 ${ }^{[67]}$ 找到了一种与Cry互作的铁硫蛋 白IscA，根据其内禀磁性等特征认为，该蛋白与Cry共同参与 
磁感应的过程, 推测它可能是潜在的磁受体蛋白(MagR), 并 提出了基于Cry/MagR蛋白复合体的磁感应模型, 又称生物指 南针模型(图4).

首先, 我们通过分析认为, 磁铁矿模型和自由基对模型 可能并不互斥. 但是在不同的感磁生物中，有时只能体现其 中一种模型的存在, 有时两者似乎又都存在. 那么, 是否存在 一个在不同物种中共同的磁受体或者磁感应分子机器呢? 考 虑现有的化学自由基对模型无法一次性获取磁场方向、倾 角和强度等全方面的地磁信息, 研究推测, 或许隐花色素蛋 白并不是磁感应机器的唯一组分, 可能还有与其互作的另一 个蛋白提供对磁场方向的检测，与隐花色素共同完成感磁过 程. 我们将这个未知的蛋白命名为 MagR, 并预测它可能是金 属结合蛋白, 就已有的蛋白质相关研究来看, 铁结合蛋白或 铁硫簇蛋白非常符合预期. 随后, 选取果蝇为研究对象, 经过 全基因组范围内的多轮笁选，找到了14个候选铁结合或者铁 硫蛋白. 再通过双标记和串联共纯化实验发现, 这 14 个候选 蛋白中有 9 个在果蝇头部与Cry共表达. 其中只有 1 个蛋白(果 蝇CG8198)与Cry有稳定的相互作用且可被Cry共纯化. 该蛋 白质(MagR)与大肠杆菌的铁硫蛋白IscA1同源，但是IscA此 前未被报道有磁性特征. 接着, 在不同物种间重复 Cry 和 MagR的共纯化实验发现，Cry与MagR之间的互作呈高度保 守性. 而进一步的电子显微镜结构研究和计算机建模结果显 示，20个MagR线性聚合呈棒状多聚体，位于复合体的中间， 10个Cry则螺旋式地结合在“棒”的外围, 推测外围缠绕的Cry 作为光受体接受光信号、而MagR则在复合物内部作为磁受 体检测磁信号，通过光磁耦合机制完成对地磁信息完整的检 测. 另外, 免疫组化实验证实了MagR和Cry在鸽子视网膜中 有高表达和共定位，尤其是在视网膜神经节细胞层有非常好 的共定位信号. 最后, 关于Cry/MagR复合物的多个磁性表征
实验均证实了该复合物的内亭磁矩符合预期：在电子显微镜 下观察发现, Cry/MagR复合物的取向在统计学上倾向于与地 磁场平行; 可以通过纳米磁珠直接富集MagR以及Cry/MagR 复合物; 最重要的是, 通过对 Cry/MagR复合物的蛋白质溶液 磁性的直接测定, 证实了该复合物内禀磁矩的存在. 这些结 果表明, Cry/MagR复合物可能构成了动物对磁场感知(磁感 应)的分子基础.

这一发现在学术界引起了广泛的兴趣和讨论 ${ }^{[69,70]}$, 比如, 光磁耦合的具体机制是什么? Cry/MagR复合物作为唯一一 个在室温条件下测到内禀磁矩的蛋白质，其背后的生物物理 学原理是什么? 这些问题都需要更多的实验证据去解答.

随后, 多个理论模型被提出试图对生物指南针假说提供 一个物理学诠释. 2018年, 有研究从电子自旋相互作用来解 释MagR的室温磁性和MagR/Cry复合物对磁场响应模式 ${ }^{[71]}$, 理论计算和模拟的结果与本课题组 ${ }^{[67]}$ 在 2016 年的观测结果 高度吻合. 最近, Xiao等人 ${ }^{[72]}$ 建立了生物指南针假说的量子 力学模型, 根据这一模型, MagR/Cry蛋白复合物可以对类似 于地磁场的微弱磁场扰动作出响应. 同时, 也有研究从 $m a g r$ 基因的系统演化和MagR/Cry蛋白复合物的三维结构动力学 模拟来理解生物指南针假说的内在机制. 如 Lu等人 ${ }^{[73]}$ 对铁硫 族结合蛋白中的A型组装蛋白(ATAP)家族中来自 321 个物种 中的MagR同源蛋白序列进行了系统演化分析，重构了这一 蛋白家族的演化历史，并对MagR(IscA1)序列中的保守基序 结合MagR多聚体结构的动力学研究, 预测 MagR的 $N$-端保守 基序Motif6可能对磁感应功能很重要.

与此同时, MagR在包括昆虫 ${ }^{[74,75]}$ 、鱼类 ${ }^{[76]}$ 、爬行类 ${ }^{[77]}$ 等动物中都得到了深人研究, 并发现在同一物种的迁徙种群 中MagR的表达远远高于不迁徙的种群 ${ }^{[74,75]}$, 这一结果从侧面 支持了MagR在生物体内作为磁受体参与了磁感应和动物迁
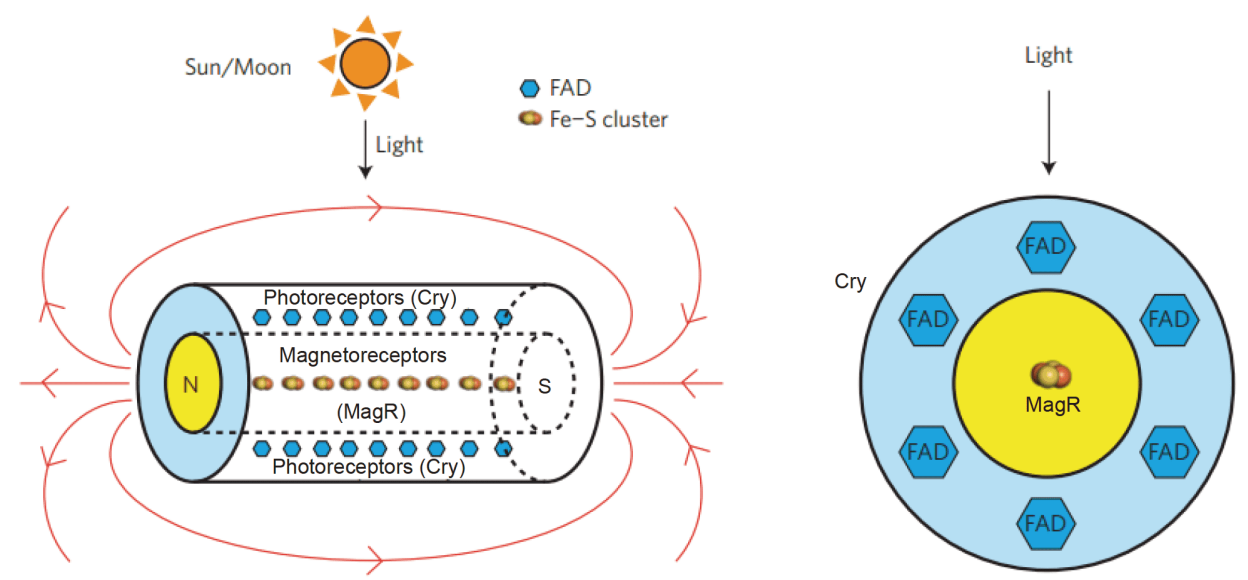

图 4 生物指南针模型 ${ }^{[67]}$. 在该模型中, 含铁硫簇的MagR线性聚合在复合体的中心作为磁受体(黄色区域), Cry则作为光受体包围在棒状核心 的外围(青色区域), 由此推测外围的Cry接受光刺激后可激发光受体中的FAD到磁受体中铁硫簇的电子传递, 即光磁耦合的磁感应机制

Figure 4 The biocompass model of animal magnetoreception ${ }^{[67]}$. In this model, a rod-like biocompass with intrinsic magnetic polarity is formed by linear polymerization of Fe-S cluster-containing magnetoreceptors (MagR) at the center (yellow), surrounded by photoreceptive cryptochromes (Cry; cyan), indicating that electron transportation from the FAD group in Cry to the Fe-S cluster in MagR upon light stimulation may be possible 
徙过程的论断. 在深人探讨生物指南针假说分子机理的同时, 基于MagR磁性的潜在应用也在探索之中，包括利用MagR作 为磁性标签进行蛋白质的分离纯化 ${ }^{[78]}$, 以及利用 MagR/Cry蛋 白质复合物构建的分子器件用于光磁的检测均取得了成功, 也佐证了 MagR以及 $\mathrm{MagR} / \mathrm{Cry}$ 的磁学特性和在动物磁感应中 可能的功能 ${ }^{[79]}$.

\section{5 生物磁感应模型小结与展望: 大一统还是 多元化?}

在既往研究中, 多种生物磁感应模型/假说被提出, 均获 得了一些实验数据的支持, 但目前尚未有任何一种模型能够 很好地解释动物迁徙和生物导航中的所有问题, 也没有任何 一个模型得到了领域内所有科学家的公认. 随着学科发展和 研究深人, 未来是否会有一个统一的生物磁感应理论的出现, 科学家们也有着不同的见解. 磁感应是一个典型的交叉科学 的研究领域, 不同的研究背景也可能影响科学家对这一问题 的看法.

物理学家对于自然规律一致性的追求，也反映在磁感应 这一物理背景明显的交叉领域中. 一部分科学家倾向于认为 生物可能通过一个统一的机制或称为大一统理论 (a grand unified theory)来感应磁场变化, 然后再通过不同的导航策略 来适应不同环境下的需求, 这一思想在一些综述中均有所体 现 ${ }^{[80-82]}$. 甚至在2016年MagR/Cry蛋白复合物的发现, 也引发 了对大一统理论的思考, Lohmann ${ }^{[83]}$ 指出, MagR/Cry蛋白质 复合物可能提供了一种普遍统一的磁感应结构 (universal magnetic-sensing structure), 可能被不同的动物采纳并在不同 的生态环境下去检测不同的磁场参数.

不过，大一统的思想并不被所有科学家接受. 让我们回 到最基本的问题：磁感应能力在生物的演化和适应中到底扮 演着什么样的角色呢？生物演化的目的是适应不同的环境, 从而实现个体生存和种族繁衍. 磁感应能力的出现和动物迁 徙行为息息相关. 动物迁徙是某些动物在进化过程中形成的, 为了某种生理需求，周期性地在特定时间，沿着一定线路在 繁殖地和越冬地之间进行的集群性长距离移动行为. 磁感应 和生物导航能力使得这种长距离的迁徙成为可能. 但地球上 的生物多种多样, 所处环境包括磁环境各不相同. 比如说, 由 于海水运动(海浪、海流、内波等), 海洋生物所面对的磁场 除了地磁场, 还有海洋背景磁场的叠加 ${ }^{[84]}$, 同时由于洋流的 影响和海洋的特殊环境，导致洄游中的海洋生物和迁徙中的 鸟类从环境获取的导向信号(guidance cues)也大不一样. 有可 能不同的物种在不同的环境下，在不同的历史年代中独立演 化出不同的磁感应机制和迥异的导航策略.

但湖本归源，“大一统”和“多样性”其实原本就是不同层 面上的问题. 不管是什么样的磁受体, 从本质上来看, 磁感应 的机理都可以统一到电子和外界磁场的相互作用这一微观 行为上来. 而磁感应机制的多样性则更多地体现在具体的分
子水平、细胞水平乃至个体水平. 当然，生物到底通过什么 样的磁受体和什么样的机制实现对地磁场的感应，是否存在 一个统一的机制适用于所有生物，关于这一问题的争论和思 考必然还将继续下去. 事实上，自鲨鱼的劳伦氏呈腹被发现， 人们花了近 300 年才明确了其在电磁诱导方面的作用; 自二 十世纪七八十年代磁铁矿假说的流行，直到 30 多年后才证实 鸽子喙部富铁细胞只是巨噬细胞; 自 Schulten推测鸟类的磁 感应机制涉及了自由基对的纠缠态这一观点，直到20多年后 相关的实验证据才浮出水面. 而这一过程，从一开始就伴随 着“突破-希望-质疑-新突破-新希望-新质疑”的循环. 对动物 磁感应和生物导航的各种假说与模型的确证及甄别，抑或新 的模型和假说的提出与验证, 都将是一个任重而道远的科学 探索过程.

\section{3 人类与磁感应}

随着生物磁感应的研究逐渐丰富, 科学家们开始想到: 人类有没有磁感应能力? 对这一个引人人胜的问题的探究, 从研究历史来看, 可能也最能体现磁感应这一领域在质疑与 希望中前行的特点, 值得后来的科学家为此写上重重的一笔.

最早提出人类是否如同迁徙鸟类一般在潜意识里具有 某种方向感这一问题，可以追溯到1873年达尔文应Nature邀 请写的一篇题为“Origin of certain instincts”的评述 ${ }^{[85]}$. 达尔 文指出, 在北西伯利亚, 当地人群可以在茫茫的雪野中进行 长途跋涉并抵达某个目的地(the natives kept a true course towards a particular spot), 期间他们会不停地调整前进方向而 不依赖于任何已知的路标(with no guide in the heavens or on the frozen sea), 他认为这种识别方向的能力可能出自一种潜 意识的本能.

但真正对人类磁感应的研究则发生在 100 多年以后，同 样也发生在磁感应研究的黄金时代也即 20 世纪 80 年代. 英国 曼彻斯特大学的Robin Baker教授设计了一个简单的行为学 实验，将被蒙上眼睛的志愿者们通过曲折的路线送至 $10 \mathrm{~km}$ 外后询问他们起点的方向, 令人惊讶的是从统计数据来看大 家多数都能指对. 随后在眼罩中放人条形磁铁和黄铜棒(对 照)，重复实验，结果发现，前者会对志愿者方向指认产生干 扰, 而后者无影响, 这一实验发表在1980年的Science上, 随后 引起了轰动 ${ }^{[86]}$. 然而, 该实验并未得到其他课题组的独立重 复, Robin Baker本人也未能重现自己的实验结果，从而遭受 广泛的质疑.

无可否认，人类究竟是否具备磁感应的能力，人类戏称 的对磁场和方向的“第六感”到底有没有潜在的科学基础，截 至目前还是一个神秘而未知的科学问题. 即使 20 世纪无法重 复的行为学实验为这一话题蒙上了阴影，科学家们也没有放 弃对它的不断求证. 近期几个代表性的工作值得关注. 基于 人类视网膜上也有丰富的隐花色素蛋白，2011年，Steven M. Reppert实验室的Foley等人 ${ }^{[87]}$ 将人的 $C r y$ 基因导人 $C r y$ 基因缺 
陷的果蝇中, 发现果蝇又恢复了磁感应能力. 这可能表明, 人 的 Cry 基因具有光敏磁传感器分子功能. 此外, 2019年, Joeseph Kirschivink实验室的Wang等人 ${ }^{[88]}$ 使用一种新型法拉第 笼产生高度可控的均匀磁场. 随后, 通过对 34 名身处其中的 志愿者脑电波检测发现, 磁场的改变可以使他们的alpha脑电 波处于 $\alpha$-ERD的模式. 这似乎表明大脑的alpha脑电波对磁场 的响应, 尽管他们本人并没有感觉到任何的异样. 这一研究 可能暗示着人类的潜意识或许是能够感应到地磁场, 只不过 在进化的过程中通过自动“调零”而忽略了, 就像大多数情况 下我们不会意识到自己在呼吸一样. 同年, 韩国Kwon-Seok Chae实验室招募了 41 个志愿者, 让受试者坐在转椅上感知磁 场并指示方向 ${ }^{[89,90]}$. 受试者先后在非饥饿状态和饥饿状态下, 排除视觉和听觉信息, 指示指定方向(北或东). 结果发现, 只 有饥饿的男性能表现出明显的方向感(正确指示方向). 且通 过完全蒙住眼睛和戴特定波长过滤眼镜的对照试验, 他们发 现, 蓝光是受试者感知磁极/方向的必要条件. 整个过程采用 的是双盲法实验, 实验操作者知道受试者是否被蒙住了眼 睛、是否戴波长过滤眼镜，以及是否与食物有关，但并不知 道电脑系统所控制的磁场方向; 数据分析人员则不知道手上 的数据是来自男性或女性、饥饿或未饥饿, 以及食物相关/非 相关受试者. 因此, 他们得出结论: 饥饿的男性可以依赖蓝光 感知磁场, 且感磁过程利用的似乎是磁倾角罗盘. 有意思的 是，2019年发表的这两篇关于人类磁感应的论文 ${ }^{[88,89]}$, 都经 历过至少2 3年艰难的投稿和审稿过程，表明了当前的磁感 应领域对人类磁感应这一主题极其谨慎的态度.

对于人类是否真的具有磁感应能力, 从 1873 年的达尔文 到今天的我们, 仍然没有找到一个确切的答案. 从进化来看, 从智人出现到农业出现, 在城镇和村庄出现之前, 人类经历 了为了生存而不得不在复杂的野外环境中受食和长距离迁 徙的过程, 那么当时的人类是否也具有如同今天信鸽归巢一 般的生物导航能力? 而随着人类文明的发展, 农村和城镇的 出现, 长距离导航已经不再是生死敒关的问题了, 我们又是 否慢慢地丢失了这一功能, 只留下一些进化的痕迹和潜意识 中对磁场的感知, 如Kirschivink课题组 ${ }^{[88]}$ 指出的alpha脑电波 对磁场的响应?

\section{4 生物磁感应的新近研究}

除了上述提到的几大磁感应模型外, 近几年在生物磁感 应领域陆续也有一些新的、不同的磁受体模型被报道，虽影 响力不及上述几种主流的磁感应模型，但也值得关注. 2018 年, Krishnan等人 ${ }^{[91]}$ 在玻璃鲶鱼(Kryptopterus bicirrhis)中分 离鉴定到了一个对电磁场敏感的蛋白基因, 他们称之为电磁 感知基因(electromagnetic perceptive gene, EPG), 随后在毕赤 酵母中克隆EPG, 确定其编码的蛋白对电动势有响应, 并将此 作为磁受体. 他们还发现, EPG 可应用于磁遗传学, 通过将其 表达至靶细胞便可在特定磁场激活下实现对细胞的无线操
控. 2019年, Shao等人 ${ }^{[92]}$ 在通过全基因组关联研究(GWAS)揭 示鸽子归巢能力的潜在机制时，声称找到了另一个可能作为 磁受体的蛋白一 GSR(编码谷胱甘肽-二硫键还原酶). 通过 对信鸽基因组进行大数据比对分析发现，信鸽中的GSR在信 鸽个体中存在表达差异, 且在归巢鸽中表现出更高的表达水 平. 另外, 在体外的磁场刺激过程中, 表达鸽子GSR的细胞内 钙离子浓度增加, 反映了生物体对磁场的响应. 因此, 基于基 因组的大数据分析和体外实验，他们认为GSR可能参与了鸽 子的磁感应.

另外, 关于感磁过程, 也有一些不同观点. 研究发现, 各 类生物体中都存在活性氧, 而磁场会影响活性氧水平 ${ }^{[93]}$. 因 此, 有研究认为, 超氧可替代黄素自由基作为磁敏受体参与 生物的磁感应. 2019年, Player和Hore ${ }^{[94]}$ 通过对黄素蛋白-超 氧自由基对进行自旋动力学建模分析认为, 超氧存在较高的 可能性参与了生物磁感应过程. 他们扩展了经典的自由基对 化学模型, 提出在有氧条件下, 可以通过氧化被还原的黄素 蛋白使超氧分子介人感磁过程. 同年, Bell和Robinson ${ }^{[95]}$ 则是 基于合成磁感受器的最新实验提出，旋转磁场的热效应可能 是自然磁感应的潜在机制. 他们引人了旋磁热效应受体的概 念，表示由于旋磁热效应，纳米粒子磁化而产生的热量可能 会激活附近的热感受器(热敏蛋白), 再通过进一步的信号传 导使动物能够检测到地球磁场的特征. 关于旋转磁场对生物 的影响, Xu等人 ${ }^{[96]}$ 也通过实验指出, 旋转磁场能减缓人脐静 脉内皮细胞衰老和延长秀丽线虫寿命. 这些研究表明, 某些 生物体内的细胞似乎确实能对旋转磁场作出某种响应，鉴于 以往关于生物磁感应的研究大都是在稳恒磁场下进行的, 这 为今后的磁感应研究提供了一个新的实验设计思路和方向.

综上来看, 研究者仍在尝试寻找新的磁受体或者验证现 有的磁感应假说, 并试图从不同的角度、用不同的方式探寻 生物的磁感应过程, 且时有新的发现被报道, 也有新的质疑 不断浮现. 这充分表明，生物磁感应这一基本生物学问题的 重要性正在引起越来越多的关注.

\section{5 生物磁感应研究之独特性, 面临的问题与 挑战}

磁感应作为生物的一种特殊感觉系统——磁感觉 (magnetic sense), 具有与其他感觉系统截然不同的特点. 而这些独 特性, 决定了磁感应的研究从一开始就走上了与我们熟知的 生物学截然不同的发展路线.

\section{1 很不生物学的磁感应研究历史和现状}

感官生物学常规的研究思路和研究历程往往如此: 首先 确定地知道某种特定感觉系统的存在, 以及是何种感觉器官 (如视觉的眼睛, 嗅觉的鼻子), 在此基础上, 科学家得以鉴定 出该感觉系统的感受器细胞、神经通路以及大脑中与该感 觉相关的区域. 在感受器细胞被鉴定出来的基础上，通过遗 
传学和其他分子生物学的方法鉴定出感觉受体的基因及其 编码的蛋白, 阐述其感受信号的分子机理. 这一研究思路也 代表了现代生物学思维主导下的科学研究历程.

然而, 磁感应正在经历与此完全不同的研究历程. 首先, 与其他几乎所有的感觉系统不同的是: 从170多年前, Middendorf ${ }^{[6]}$ 发表的第一个动物迁徙的论文开始, 到50多年前 Wiltschko和Merkel ${ }^{[9]}$ 证明鸟类迁徙是基于对地球磁场的感知 而实现，时至今天，科学家仍未确丵无疑地鉴定出动物用来 感知磁场的器官到底是什么, 神经通路是什么, 大脑中与磁 感应相关的部分在哪里? 在磁感应这一神秘的感觉系统研究 历程中，这三大经典的生物学要素全部缺失，使得利用常规 的生物学方法来鉴定磁感应受体(简称磁受体, magnetoreceptor)成为几乎不可能的任务. 因此, 寻找磁受体的研究从一开 始就是以推测和奇思妙想为主导的过程, 在这一过程中并未 遵循生物学的常规研究思路和方法, 反而与物理学理论的诞 生更为相似. 目前关于磁受体的几种主流假说均如此. 以化学 自由基对假说的建立为例：首先提出科学问题——动物如何 感知微弱的地磁场; 接着提出一个物理模型和假设——电子 自旋的单态和三重态的转换可以被微弱磁场影响, 这种机制 有可能被生物采用来感知微弱的地磁场 ${ }^{[17]}$; 然后根据这一假 说来寻找生物体内可能满足这一条件的分子 ${ }^{[58]}$. MagR的发现 与生物指南针假说的提出也大体上遵循了这一思维范式 ${ }^{[67]}$.

我们只有理解了磁感应研究领域的这一特殊性, 才能很 好地理解目前磁感应研究中面临的困境. 而这一领域的特殊 性和困境，同时也为我们提供了巨大的机遇. 通过不同学科 的交叉和融合，可以给我们带来不同思想的碰撞、不同的科 研思路和思维范式、不同领域的先进技术，使得我们可能会 找到新的突破口。也正是这一特殊性，使得这一领域吸引了 无数的天才科学家以他们的激情和无穷的想象力在推动着 这个领域的发展。

\section{2 基因编辑之光尚未照进的领域}

在经典的生物学领域中，体内(in vivo)基因敲除(knockout)、基因敲人(knock-in)或者新近发展的基因编辑(gene editing)是研究和验证某个特定基因功能的金标准. 随着较早 期的TALEN技术和新近的CRISPR-Cas系统的发展，科学家 在模式生物中已经能常规化地实现对特定基因的敲除、敲 低、敲人和编辑了. 然而, 还有很多的非模式生物, 科学家虽 然历经尝试, 但迄今为止, 从未获得成功. 这些非模式生物是 基因编辑之光尚未照进的领域 ${ }^{[97]}$.

对已有的几种磁感应假说的验证，尤其是对基于Cry蛋 白的自由基对假说和基于 MagR以及 $\mathrm{MagR} / \mathrm{Cry}$ 复合物的生物 指南针假说，最终都将依赖于体内基因敲除实验的验证．然 而, 目前在实验室, 唯有迁徙鸟类(如知更鸟等)和具有归巢行 为鸟类(如信鸽)的磁场定向实验因为被多个实验室广泛重复 而争议较少. 但是, 鸟类作为一种非模式生物, 其基因敲除的
难度极大. 究其原因, 鸟类因为其独特的生殖系统使得科学 家对处于“1-细胞期”阶段的受精卵进行基因编辑几乎不可 能. 迄今为止, 成功的例子仅仅只有在鸡中的少数几例报 道 ${ }^{[98-101]}$ 和 2019年在鹤敦中的一例报道 ${ }^{[102]}$. 以家鸡为例，基 因编辑需要 3 个关键步骤: 原生殖细胞(PGC)的分离和体外培 养; 在体外对PGCs的基因编辑; 在内源PGC通过循环迁移到 生殖崉的胚胎早期将体外编辑过的PGC注射到胚外血管中. 整个过程需要非常精湛的实验技能，而且成功率极低，目前 只有在家鸡和鹤墪这种已有相对较为成熟的细胞学和遗传 学基础, 且每年产卵 300 枚以上的鸟类中才有可能实现 ${ }^{[102]}$.

这一困难，也导致了磁感应领域的研究很难受益于当下 高速发展的转基因和基因编辑等现代遗传学的手段，因此在 其他感官生物学突飞猛进的时代, 磁感应的研究仍然举步 维艰.

\section{3 不可回避的物理学问题与交叉学科可能带来的 突破}

生物磁感应和生物导航不只是一个生物学问题, 更是一 个物理学问题. 现有的假说常常在这两者之间互相矛盾，具 体常常表现为物理学自洽和生物学验证的矛盾, 以及实验观 测与理论推导的矛盾. 如: 磁铁矿颗粒假说满足了物理学的 磁响应问题，也能很好地适用于趋磁细菌的感磁过程，但对 进化中更为复杂的生物 (如鸟类和哺乳类)是否也适用? 磁铁 矿颗粒虽然在很多物种中都有鉴定，但从生物学上尚未建立 起磁铁矿颗粒的存在与动物磁感应之间的关联; 基于Cry蛋 白的自由基对假说满足了量子物理的磁倾角检测问题，但无 法解释生物学观测的鸟类方向识别能力问题，也无法解释微 观的电子自旋状态如何能被细胞信号识别的问题；基于 $\mathrm{MagR} / \mathrm{Cry}$ 蛋白复合物的生物指南针假说满足了方向识别问 题和磁倾角检测问题，但单纯从蛋白质中铁原子的数量无法 用经典物理模型解释实验中观测的蛋白质磁性起源问题 ${ }^{[69]}$. 而且，无论对自由基对假说还是生物指南针假说，在室温或 者生理条件下分子热运动带来的热扰动对磁场分子效应的 干扰都是一个难以回避的物理学问题, 生物以什么样的机制 来放大这种对单分子或者电子自旋的微弱磁效应，则是这个 领域亟须解决的问题之一. 虽然最近提出的关于 MagR/Cry蛋 白质复合物的量子力学诠释提出，该复合物对磁场的扰动将 非常敏感, 可以满足在生理温度下对微弱地球磁场的检测 ${ }^{[72]}$, 但仍需进一步的理论和实验上的验证.

在传统的生物学系统中, 我们已知化学信号的感受, 如 激素的作用、嗅觉，基本的信号接收和传递机制可以概括为: 一个受体与一个或少数几个配体结合而被激活，这一模式可 以称为单一事件(single event), 受体激活后启动级联放大反 应，从而实现从“ $1 \rightarrow N$ ”的信号放大. 而磁场的感知可能采取 完全不同的机制. 因为磁场对生物体是“透明”的，在磁场下 的所有分子包括磁受体都将同时受到磁场的作用，也即，在 
磁场下的所有磁受体都将同时被磁场激活，这一模式可以称 为群体事件(massive events). 在这样一个系统中, 所有的磁受 体在某种浓度下或许有可能呈现协同效应, 从而具有复杂系 统(complex system)的特征, 导致微弱的地磁场信息感知, 有 可能通过 “ $N \rightarrow N^{N}$ ”的方式被放大? 这些问题的解答都不太可 能单纯依靠生物学家或者物理学家来提供答案，亟需不同学 科的交叉和融合来取得突破.

同时, 从技术方法来看，同样也依赖于交叉学科的突破. 生物磁感应的研究乃至磁生物学的研究, 首先是一个生物学 的问题, 很多的技术方法都需要在生物学和生物样品中得到 实现. 比如, 对生物样品弱磁性的测量和生物大分子的微观 磁学性质的研究就是一个极其具有挑战性的工作. 尽管在物 理学领域对微观磁学研究有很多有力的工具和高灵敏度的 检测方法，如NV色心(nitrogen-vacancy center)技术、无自旋 交换碰撞迟豫原子磁力计(SERF)、超导量子干涉磁强计 (SQUID)等, 但大部分都局限于对固体材料的研究, 弱磁性的 检测也常常需要在低温和超低温下进行探测, 而生物样品如 蛋白质则依赖于溶液状态和生理温度发挥功能. 如果我们能 将先进的磁学研究工具应用于生物学领域, 那么在未来 可能给生物磁感应研究带来新的突破. 从生物学本身来说, 磁感应的研究也有赖于动物行为学、神经生物学、系统生 物学、生物电磁学和生物物理学等多学科多领域的交叉 融合.

另外, 在利用人工磁场研究生物磁感应时, 应注意尽可 能地模拟地磁场的情况. 因为生物对磁的感应可能像人对颜 色、声音的感应是一样的, 只有在一定磁感应强度范围内(或 其他磁条件限制下)才可实现对磁场的感应, 超出该范围的则 无法感知, 就像人类无法看见红外线、紫外线和无法听见频 率低于 $20 \mathrm{~Hz}$ 或超过 2 万 $\mathrm{Hz}$ 的声音一样.

\section{6 结语}

地球上的许多生物在几十亿年的进化过程中发展出利 用地磁场以及其他信息在海陆空不同空间、不同尺度上进 行精确定向导航的令人惊叹的能力. 磁感应和生物导航原理 的阐明是生命科学中引人注目的未解之谜和自然科学领域 尚未摘取的一颗明珠, 它可能引发物理学新模型的提出、生 物学新机理的发现. 随着生物导航机理的最终诠释, 或将催 生新一代的仿生导航仪和定位仪的出现及新一代生物磁控 技术的发展.

从19世纪 50 年代首次报道动物迁徙似乎与地球磁场相 关, 生物磁感应的研究一直在充满质疑和希望的道路上前行. 历经了近半个世纪以来的高速发展，生物磁感应机制仍然成 谜, 使得这一领域独具魅力令人激动, 而吸引了一大批野心 勃勃的科学家在此探索、耕耘、播种希望, 也期待着更多不 同研究背景科学家的涌人.

在本文正式刊发前，Nature以封面文章报道了动物磁感 应领域的一个新进展. 我们课题组联合Hore和Mouritsen等多 个课题组提出了基于 $\mathrm{Cry} 4$ 蛋白的新的量子生物学模型 ${ }^{[103]}$. 该 研究首次发现迁徙鸟类如欧洲知更鸟的 Cry4蛋白对磁场的 敏感性显著大于非迁徙鸟类的Cry4蛋白，并对已有的自由基 对假说进行了新的扩展, 认为在FAD和邻近的 4 个保守色氨 酸(称为色氨酸四联体Trp-tetrad)之间的电子传递同时承担了 “磁感应”和“信号传递”两种不同的功能，根据磁共振光谱学 实验和量子计算的结果，提出了第四个色氨酸对信号传递至 关重要，暗示着可能有另一个蛋白与Cry4相互作用参与这一 复杂的过程, 至于是否是曾经报道的MagR还是其他未知的 互作蛋白则是另一个令人人胜的问题. 这一研究是否在未来 促成自由基对假说和生物指南针假说的融合，或发现新的机 制则尚未可知.

\section{推葆阅读文献}

1 Yang P L, Xie C. Magnetoreception in animals (in Chinese). Science, 2017, 69: 23-27 [杨珮琳, 谢灿. 动物的磁感应. 科学, 2017, 69: 23-27]

2 Elsasser W M. Induction effects in terrestrial magnetism. Part III. Electric modes. Phys Rev, 1947, 72: 821

3 Bullard E C. The magnetic field within the Earth. Proc R Soc London Ser A, 1949, 197: 433-453

4 Zhu X L, Wang J Y. The effect of geomagnetism on biomagnetism (in Chinese). Chin J Nat, 2013, 35: 200-206 [朱晓璐, 王江云. 地磁场与生物 的磁感应现象. 自然杂志, 2013, 35: 200-206]

5 Tian L X, Pan Y X. The geomagnetic field effects on animals: A review (in Chinese). Chin Sci Bull, 2019, 64: 761-772 [田兰香, 潘永信. 地磁场 与动物感磁. 科学通报, 2019, 64: 761-772]

6 Middendorf A T V. Die Isepiptesen Russlands: Grundlagen zur Erforschung der Zugzeiten und Zugrichtungen der Vögel Russlands. St. Petersburg: Buchdruckerei der K. Akademie der Wissenschaften, 1855

7 McFadden J, Al-Khalili J. Life on the Edge: The Coming of Age of Quantum Biology. New York: Crown Publishing Group, 2016 [吉姆·艾尔-哈 利利, 约翰乔·麦克法登. 神秘的量子生命. 杭州: 浙江人民出版社, 2016]

8 Yeagley H L, Whitmore F C. A preliminary study of a physical basis of bird navigation. J Appl Phys, 1947, 18: 1035-1063

9 Wiltschko W, Merkel F W. Orientierung zugunruhiger Rotkehlchen im statischen Magnetfeld. Verh Dtsch Zool Ges, 1966, 59: 362-367

10 Wiltschko W, Wiltschko R. Magnetic compass of European robins. Science, 1972, 176: 62-64

11 Emlen S T, Wiltschko W, Demong N J, et al. Magnetic direction finding: Evidence for its use in migratory indigo buntings. Science, 1976, 193: 
505-508

12 Blakemore R. Magnetotactic bacteria. Science, 1975, 190: 377-379

13 Monteil C L, Lefevre C T. Magnetoreception in microorganisms. Trends Microbiol, 2020, 28: 266-275

14 Gould J L, Kirschvink J L, Deffeyes K S. Bees have magnetic remanence. Science, 1978, 201: 1026-1028

15 Kirschvink J L, Gould J L. Biogenic magnetite as a basis for magnetic field detection in animals. Biosystems, 1981, 13: 181-201

16 Lowenstam H A. Lepidocrocite, an apatite mineral, and magnetite in teeth of chitons (Polyplacophora). Science, 1967, 156: 1373-1375

17 Schulten K, Staerk H, Weller A, et al. Magnetic field dependence of the geminate recombination of radical ion pairs in polar solvents. Z für Physikalische Chem, 1976, 101: 371-390

18 Schulten K, Wolynes P G. Semiclassical description of electron spin motion in radicals including the effect of electron hopping. J Chem Phys, 1978, 68: 3292-3297

19 Quinn T P. Evidence for celestial and magnetic compass orientation in lake migrating sockeye salmon fry. J Comp Physiol, 1980, 137: 243-248

20 Phillips J B. Two magnetoreception pathways in a migratory salamander. Science, 1986, 233: 765-767

21 Hsu C Y, Li C W. Magnetoreception in honeybees. Science, 1994, 265: 95-97

22 Ernst D A, Lohmann K J. Effect of magnetic pulses on Caribbean spiny lobsters: Implications for magnetoreception. J Exp Biol, 2016, 219: 18271832

23 Endres C S, Putman N F, Ernst D A, et al. Multi-modal homing in sea turtles: Modeling dual use of geomagnetic and chemical cues in islandfinding. Front Behav Neurosci, 2016, 10: 19

24 Wang Y, Pan Y, Parsons S, et al. Bats respond to polarity of a magnetic field. Proc R Soc B, 2007, 274: 2901-2905

25 Jacklyn P M, Munro U. Evidence for the use of magnetic cues in mound construction by the termite Amitermes meridionalis (Isoptera: Termitinae). Aust J Zool, 2002, 50: 357

26 Němec P, Altmann J, Marhold S, et al. Neuroanatomy of magnetoreception: The superior colliculus involved in magnetic orientation in a mammal. Science, 2001, 294: 366-368

27 Hart V, Nováková P, Malkemper E P, et al. Dogs are sensitive to small variations of the Earth's magnetic field. Front Zool, 2013, 10: 80

28 Wiltschko R, Wiltschko W. Magnetoreception. Bioessays, 2006, 28: 157-168

29 Johnsen S, Lohmann K J. Magnetoreception in animals. Phys Today, 2008, 61: 29-35

30 Giancoli C D. Physics: Principles with Applications. 5th ed. Boston: Pearson, 1997. 623-624

31 Chen Y C. University Physics (Volume 2) (in Chinese). Beijing: Beijing Institute of Technology Press, 2016 [陈颖聪. 大学物理(下册). 北京: 北 京理工大学出版社, 2016]

32 Kalmijn A J. The electric sense of sharks and rays. J Exp Biol, 1971, 55: 371-383

33 Paulin M G. Electroreception and the compass sense of sharks. J Theor Biol, 1995, 174: 325-339

34 Nimpf S, Nordmann G C, Kagerbauer D, et al. A putative mechanism for magnetoreception by electromagnetic induction in the pigeon inner ear. Curr Biol, 2019, 29: 4052-4059.e4

35 Shao Z Y, Xu G L. Research progress on biological magnetoreception mechanism (in Chinese). Chem Life, 2019, 39: 838-848 [邵震宇, 徐国良. 生物磁感应机制的研究进展. 生命的化学, 2019, 39: 838-848]

36 Kuterbach D A, Walcott B, Reeder R J, et al. Iron-containing cells in the honey bee (Apis mellifera). Science, 1982, 218: 695-697

37 Eder S H K, Cadiou H, Muhamad A, et al. Magnetic characterization of isolated candidate vertebrate magnetoreceptor cells. Proc Natl Acad Sci USA, 2012, 109: 12022-12027

38 Fleissner G, Holtkamp-Rötzler E, Hanzlik M, et al. Ultrastructural analysis of a putative magnetoreceptor in the beak of homing pigeons. J Comp Neurol, 2003, 458: 350-360

39 Nichol H, Locke M, Kirschvink J L, et al. Honeybees and magnetoreception. Science, 1995, 269: 1888-1889

40 Hsu C Y, Ko F Y, Li C W, et al. Magnetoreception system in honeybees (Apis mellifera). PLoS One, 2007, 2: e395

41 Hsu C Y, Chan Y P. Identification and localization of proteins associated with biomineralization in the iron deposition vesicles of honeybees (Apis mellifera). PLoS One, 2011, 6: e19088

42 Shaw J A, Boyd A, House M, et al. Multi-modal imaging and analysis in the search for iron-based magnetoreceptors in the honeybee Apis mellifera. R Soc Open Sci, 2018, 5: 181163

43 Walcott C, Gould J L, Kirschvink J L. Pigeons have magnets. Science, 1979, 205: 1027-1029

44 Beason R C, Nichols J E. Magnetic orientation and magnetically sensitive material in a transequatorial migratory bird. Nature, 1984, 309: 151153

45 Mora C V, Davison M, Martin Wild J, et al. Magnetoreception and its trigeminal mediation in the homing pigeon. Nature, 2004, 432: 508-511

46 Walker M M, Diebel C E, Haugh C V, et al. Structure and function of the vertebrate magnetic sense. Nature, 1997, 390: 371-376

47 Treiber C D, Salzer M C, Riegler J, et al. Clusters of iron-rich cells in the upper beak of pigeons are macrophages not magnetosensitive neurons. 
Nature, 2012, 484: 367-370

48 Edelman N B, Fritz T, Nimpf S, et al. No evidence for intracellular magnetite in putative vertebrate magnetoreceptors identified by magnetic screening. Proc Natl Acad Sci USA, 2015, 112: 262-267

49 Liang C H, Chuang C L, Jiang J A, et al. Magnetic sensing through the abdomen of the honey bee. Sci Rep, 2016, 6: 1-7

50 Lambinet V, Hayden M E, Reigl K, et al. Linking magnetite in the abdomen of honey bees to a magnetoreceptive function. Proc R Soc B, 2017, 284: 20162873

51 Hsu C Y, Lo H F, Mutti N S, et al. Ferritin RNA interference inhibits the formation of iron granules in the trophocytes of worker honey bees (Apis mellifera). Sci Rep, 2019, 9: 1-7

52 Alves O C, Srygley R B, Riveros A J, et al. Magnetic anisotropy and organization of nanoparticles in heads and antennae of neotropical leaf-cutter ants, Atta colombica. J Phys D-Appl Phys, 2014, 47: 435401

53 Pan W, Wan G, Xu J, et al. Evidence for the presence of biogenic magnetic particles in the nocturnal migratory brown planthopper, Nilaparvata lugens. Sci Rep, 2016, 6: 1-13

54 Wajnberg E, Rossi A L, Esquivel D M S. Titanium and iron titanium oxide nanoparticles in antennae of the migratory ant Pachycondyla marginata: An alternative magnetic sensor for magnetoreception? Biometals, 2017, 30: 541-548

55 Kong L J, Crepaz H, Górecka A, et al. In-vivo biomagnetic characterisation of the American cockroach. Sci Rep, 2018, 8: 1-7

56 Wiltschko W, Wiltschko R. Disorientation of inexperienced young pigeons after transportation in total darkness. Nature, 1981, 291: 433-434

57 Stanewsky R, Kaneko M, Emery P, et al. The cryb mutation identifies cryptochrome as a circadian photoreceptor in Drosophila. Cell, 1998, 95: 681-692

58 Ritz T, Adem S, Schulten K. A model for photoreceptor-based magnetoreception in birds. Biophys J, 2000, 78: 707-718

59 Ritz T, Thalau P, Phillips J B, et al. Resonance effects indicate a radical-pair mechanism for avian magnetic compass. Nature, 2004, 429: 177-180

60 Thalau P, Ritz T, Stapput K, et al. Magnetic compass orientation of migratory birds in the presence of a $1.315 \mathrm{MHz}$ oscillating field. Naturwissenschaften, 2005, 92: 86-90

61 Liedvogel M, Maeda K, Henbest K, et al. Chemical magnetoreception: Bird cryptochrome 1a is excited by blue light and forms long-lived radicalpairs. PLoS One, 2007, 2: e1106

62 Gegear R J, Casselman A, Waddell S, et al. Cryptochrome mediates light-dependent magnetosensitivity in Drosophila. Nature, 2008, 454: 10141018

63 Solov'yov I A, Ritz T, Schulten K, et al. A chemical compass for bird navigation. In: Masoud M, Yasser O, Greg E, et al., eds. Quantum Effects in Biology. Cambridge: Cambridge University Press, 2014. 218-236

64 Hore P J, Mouritsen H. The radical-pair mechanism of magnetoreception. Annu Rev Biophys, 2016, 45: 299-344

65 Bialas C, Jarocha L E, Henbest K B, et al. Engineering an artificial flavoprotein magnetosensor. J Am Chem Soc, 2016, 138: 16584-16587

66 Zoltowski B D, Chelliah Y, Wickramaratne A, et al. Chemical and structural analysis of a photoactive vertebrate cryptochrome from pigeon. Proc Natl Acad Sci USA, 2019, 116: 19449-19457

67 Qin S, Yin H, Yang C, et al. A magnetic protein biocompass. Nat Mater, 2016, 15: 217-226

68 Wiltschko R, Wiltschko W. Magnetoreception in birds. J R Soc Interface, 2019, 16: 20190295

69 Meister M. Physical limits to magnetogenetics. eLife, 2016, 5: e17210

70 He J L, Wan G J, Zhang M, et al. Progress in the study of giomagnetic responses of organisms (in Chinese). Prog Biochem Biophys, 2018, 45: 689-704 [贺静澜, 万贵钧, 张明, 等. 生物地磁响应研究进展. 生物化学与生物物理进展, 2018, 45: 689-704]

71 Cao Y, Yan P. Role of atomic spin-mechanical coupling in the problem of a magnetic biocompass. Phys Rev E, 2018, 97: 042409

72 Xiao D W, Hu W H, Cai Y, et al. Magnetic noise enabled biocompass. Phys Rev Lett, 2020, 124: 128101

$73 \mathrm{Lu} \mathrm{H} \mathrm{M,} \mathrm{Li} \mathrm{J} \mathrm{D,} \mathrm{Zhang} \mathrm{Y} \mathrm{D,} \mathrm{et} \mathrm{al.} \mathrm{The} \mathrm{evolution} \mathrm{history} \mathrm{of} \mathrm{Fe-S} \mathrm{cluster} \mathrm{a-type} \mathrm{assembly} \mathrm{protein} \mathrm{reveals} \mathrm{multiple} \mathrm{gene} \mathrm{duplication} \mathrm{events} \mathrm{and}$ essential protein motifs. Genome Biol Evol, 2020, 12: 160-173

74 Chang $\mathrm{H}$, Guo J L, Fu X W, et al. Molecular characterization and expression profiles of IscAl gene in a long-distance migrant, Agrotis segetum. J Asia-Pac Entomol, 2018, 21: 1299-1306

75 Chang H, Fu X, Zhao S, et al. Molecular characterization, tissue, and developmental expression profiles of MagR and cryptochrome genes in Agrotis ipsilon (Lepidoptera: Noctuidae). Ann Entomol Soc Am, 2017, 110: 422-432

76 Zhou Z, Peng X, Chen J, et al. Identification of zebrafish magnetoreceptor and cryptochrome homologs. Sci China Life Sci, 2016, 59: 1324-1331

77 Zhang P, Liu Y, Wang M, et al. Chinese mitten crab (Eriocheir sinensis) iron-sulphur cluster assembly protein 2 (EsIscA2) is differentially regulated after immune and oxidative stress challenges. Dev Comp Immunol, 2018, 84: 343-352

78 Jiang M, Zhang L, Wang F, et al. Novel application of magnetic protein: Convenient one-step purification and immobilization of proteins. Sci Rep, 2017, 7: 13329

79 Xue L, Hu T, Guo Z, et al. A novel biomimetic magnetosensor based on magneto-optically involved conformational variation of MagR/Cry4 
complex. Adv Electron Mater, 2020, 6: 1901168

80 Kirschvink J L, Hagadorn J W. A grand unified theory of biomineralization. In: Bäuerlein E, ed. The Biomineralisation of Nano- and MicroStructures. Weinheim: Wiley-VCH Verlag GmbH, 2000. 139-150

81 Binhi V N, Prato F S. Biological effects of the hypomagnetic field: An analytical review of experiments and theories. PLoS One, 2017, 12: e0179340

82 Lin W, Kirschvink J L, Paterson G A, et al. On the origin of microbial magnetoreception. Natl Sci Rev, 2020, 7: 472-479

83 Lohmann K J. A candidate magnetoreceptor. Nat Mater, 2016, 15: 136-138

84 Zhang H B. Simulation of ocean background magnetic field and it's distribution in East China Sea (in Chinese). Master Thesis. Qingdao: Ocean University of China, 2008 [张海滨. 海洋背景磁场数值模拟及东中国海上层海流磁场分布. 青岛: 中国海洋大学, 2008]

85 Darwin C. Origin of certain instincts. Nature, 1873, 179: 417-418

86 Baker R R. Goal orientation by blindfolded humans after long-distance displacement: Possible involvement of a magnetic sense. Science, 1980, 210: $555-557$

87 Foley L E, Gegear R J, Reppert S M. Human cryptochrome exhibits light-dependent magnetosensitivity. Nat Commun, 2011, 2: 356

88 Wang C X, Hilburn I A, Wu D A, et al. Transduction of the geomagnetic field as evidenced from alpha-band activity in the human brain. eNeuro, 2019, 6: e0483-18

89 Chae K S, Oh I T, Lee S H, et al. Blue light-dependent human magnetoreception in geomagnetic food orientation. PLoS One, 2019, 14: e0211826

90 Chae K S, Oh I T, Lee S H, et al. Correction: Blue light-dependent human magnetoreception in geomagnetic food orientation. PLoS One, 2019, 14: e 0223635

91 Krishnan V, Park S A, Shin S S, et al. Wireless control of cellular function by activation of a novel protein responsive to electromagnetic fields. Sci Rep, 2018, 8: 8764

92 Shao Y, Tian H Y, Zhang J J, et al. Genomic and phenotypic analyses reveal mechanisms underlying homing ability in pigeon. Mol Biol Evol, 2020, 37: 134-148

93 Wang H Z, Liao Z C, Wang D M, et al. Static magnetic fields and reactive oxygen species (in Chinese). Chem Life, 2019, 39: 217-228 [王慧珍, 廖钟财, 王冬梅, 等. 静磁场与活性氧. 生命的化学, 2019, 39: 217-228]

94 Player T C, Hore P J. Viability of superoxide-containing radical pairs as magnetoreceptors. J Chem Phys, 2019, 151: 225101

95 Bell A M, Robinson J T. The rotating magnetocaloric effect as a potential mechanism for natural magnetic senses. PLoS One, 2019, 14: e0222401

$96 \mathrm{Xu} \mathrm{J}$, Liu K, Chen T, et al. Rotating magnetic field delays human umbilical vein endothelial cell aging and prolongs the lifespan of Caenorhabditis elegans. Aging, 2019, 11: 10385-10408

97 Reardon S. CRISPR gene-editing creates wave of exotic model organisms. Nature, 2019, 568: 441-442

98 Schusser B, Collarini E J, Yi H, et al. Immunoglobulin knockout chickens via efficient homologous recombination in primordial germ cells. Proc Natl Acad Sci USA, 2013, 110: 20170-20175

99 Park T S, Lee H J, Kim K H, et al. Targeted gene knockout in chickens mediated by TALENs. Proc Natl Acad Sci USA, 2014, 111: 12716-12721

100 Dimitrov L, Pedersen D, Ching K H, et al. Germline gene editing in chickens by efficient CRISPR-mediated homologous recombination in primordial germ cells. PLoS One, 2016, 11: e0154303

101 Oishi I, Yoshii K, Miyahara D, et al. Targeted mutagenesis in chicken using CRISPR/Cas9 system. Sci Rep, 2016, 6: 1-10

102 Lee J, Ma J, Lee K. Direct delivery of adenoviral CRISPR/Cas9 vector into the blastoderm for generation of targeted gene knockout in quail. Proc Natl Acad Sci USA, 2019, 116: 13288-13292

$103 \mathrm{Xu} \mathrm{J}$ J, Jarocha L E, Zollitsch T, et al. Magnetic sensitivity of cryptochrome 4 from a migratory songbird. Nature, 2021, 594: 535-540 


\title{
Magnetoreception: An exciting field of challenges, hopes, wishes and beyond
}

\author{
Peng Zhang ${ }^{1,2}$ \& Can $\mathrm{Xie}^{1,2,3^{*}}$ \\ ${ }^{1}$ High Magnetic Field Laboratory, Hefei Institutes of Physical Science, Chinese Academy of Sciences, Hefei 230031, China; \\ ${ }^{2}$ University of Science and Technology of China, Hefei 230026, China; \\ ${ }^{3}$ International Magnetobiology Frontier Research Center (iMFRC), Hefei 230031, China \\ * Corresponding author, E-mail: canxie@hmfl.ac.cn
}

The ability of animals to sense the geomagnetic field and perceive guidance cues for orientation and navigation has been a subject of lively debate since the beginning. A wealth of behavioral evidences has been accumulated and several sophisticated theoretical models including electromagnetic induction, ferrimagnetism, radical pairs model based on cryptochrome and biocompass model based on MagR and MagR/Cry protein complex have been proposed. However, the mechanism of magnetoreception remains largely unknown up to date, and thus exciting. How do migratory organisms find their way has been listed by Science as one of 125 most compelling scientific questions that cannot currently be answered, but are on the horizon. Here in this historical review, we firstly focused on examining the magnetoreception research throughout the last two centuries emerged in the literatures. We then reviewed the four major hypotheses behind this scientific mystery, and highlighted pros and cons of each hypothesis. We also discussed that if it was possible that a universal mechanism can be applied to explain all questions in animal magnetoreception, from the perspective of biodiversity and evolution.

One of the heated controversies in magnetoreception is that can human navigate by sensing the geomagnetic field? We explored the research history of human magnetoreception in this review. The question can be traced back to 1873 when Charles Darwin wrote a letter to Nature, arguing that animals including human have the "instinct" to navigate. Then after almost 100 years, Robin Baker claimed to find a human compass sense of magnetic field in "Manchester Experiments" in Science in 1980, but the replication efforts all failed for more than 30 years by other groups. This controversy topic was then re-visited in 2019 and two groups published results suggesting many humans are able to unconsciously detect changes in Earth-strength magnetic fields, which raised more questions in this field.

Putting the research history into perspective, we then discussed the unique features of biological magnetoreception, the approaches currently used in this field, the challenges we were facing and the possible solutions. We listed the contradictions in four current major models to explain the mechanism of biological magnetic sensing, and why the controversies could happen. We proposed that the pattern to perceive magnetic field should be regarded as "massive event", since all molecules/receptors would respond to the changes of external magnetic field spontaneously, which was fundamentally different than the "single event" pattern when a chemical ligand binding to its receptor. We argue that a better understanding of the differences between magnetoreception and other sensory systems would help us to resolve this scientific mystery in the future.

magnetoreception, research history, electromagnetic induction, ferrimagnetism, radical pairs, biocompass

doi: 10.1360/TB-2020-1632 